\title{
Ternary solution of sodium chloride, succinic acid and water; surface tension and its influence on cloud droplet activation
}

\author{
J. Vanhanen ${ }^{1,2}$, A.-P. Hyvärinen ${ }^{1}$, T. Anttila ${ }^{1}$, T. Raatikainen ${ }^{1}$, Y. Viisanen ${ }^{1}$, and H. Lihavainen ${ }^{1}$ \\ ${ }^{1}$ Finnish Meteorological Institute, Erik Palménin aukio 1, P.O. Box 503, 00101 Helsinki, Finland \\ ${ }^{2}$ Department of Physics, University of Helsinki, P.O. Box 64, 00014 Helsinki, Finland
}

Received: 10 March 2008 - Published in Atmos. Chem. Phys. Discuss.: 14 April 2008

Revised: 4 July 2008 - Accepted: 12 July 2008 - Published: 6 August 2008

\begin{abstract}
Surface tension of ternary solution of sodium chloride, succinic acid and water was measured as a function of both composition and temperature by using the capillary rise technique. Both sodium chloride and succinic acid are found in atmospheric aerosols, the former being main constituent of marine aerosol. Succinic acid was found to decrease the surface tension of water already at very low concentrations. Sodium chloride increased the surface tension linearly as a function of the concentration. Surface tensions of both binary solutions agreed well with the previous measurements. Succinic acid was found to lower the surface tension even if sodium chloride is present, indicating that succinic acid, as a surface active compound, tends to concentrate to the surface. An equation based on thermodynamical relations was fitted to the data and extrapolated to the whole concentration range by using estimated surface tensions for pure compounds. As a result, we obtained an estimate of surface tensions beyond solubility limits in addition to a fit to the experimental data. The parameterization can safely be used at temperatures from 10 to $30^{\circ} \mathrm{C}$. These kinds of parameterizations are important for example in atmospheric nucleation models. To investigate the influence of surface tension on cloud droplet activation, the surface tension parameterization was included in an adiabatic air parcel model. Usually in cloud models the surface tension of pure water is used. Simulations were done for characteristic marine aerosol size distributions consisting of the considered ternary mixture. We found that by using the surface tension of pure water, the amount of activated particles is underestimated up to $8 \%$ if particles contain succinic acid and overestimated it up to $8 \%$ if particles contain only sodium chloride. The surface tension effect was found to increase with increasing updraft velocity.
\end{abstract}

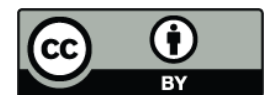

Correspondence to: J. Vanhanen (joonas.vanhanen@fmi.fi)

\section{Introduction}

Indirect effect of aerosol particles to the atmosphere (the cloud albedo effect) is currently the most uncertain piece in the climate change puzzle (IPCC, 2007). In order to understand quantitatively how aerosols and clouds interact, the physico-chemical properties of aerosols have to be known. As the atmospheric aerosols have highly heterogeneous properties and there are only limited set of measurements characterizing them, these properties have to be treated in an approximative manner in numerical models. For example surface tension of pure water is often used in air parcel models simulating the cloud formation process (Anttila et al., 2002; Kanakidou et al., 2005).

It is known that a large fraction of aerosol particles is inorganic salts (Dusek et al., 2006; McFiggans et al., 2005). Owing to their hygroscopicity, salt particles act as efficient cloud condensation nuclei (CCN). Measurements of chemical composition of aerosol particles have shown also that, in addition of inorganic salts, an extensive number of both water-soluble and water-insoluble organic acids are present in the aerosol phase (Legrand et al., 2007). They are formed for example via gas to particle conversion that results from the oxidation of volatile organic compounds (Kroll and Seinfeld, 2008). Also organics at the sea surface can be intercorporated into the particle phase when sea salt particles are formed via bubble bursting (Gershey, 1983; Ellison et al., 1999; Tervahattu et al., 2002a, b). Soluble organic acids have also found to be able to act as moderately active $\mathrm{CCN}$ (Cruz et al., 1997; Bilde et al., 2004; Varga et al., 2007).

Surface active compounds are compounds that tend to concentrate to the surface of a liquid solution and therefore lower the surface tension of the solution. Organic acids are often surface active. According to Köhler theory (Köhler, 1936), a decrease in surface tension induces a decrease in the critical supersaturation of a droplet. This means that organic acids

Published by Copernicus Publications on behalf of the European Geosciences Union. 


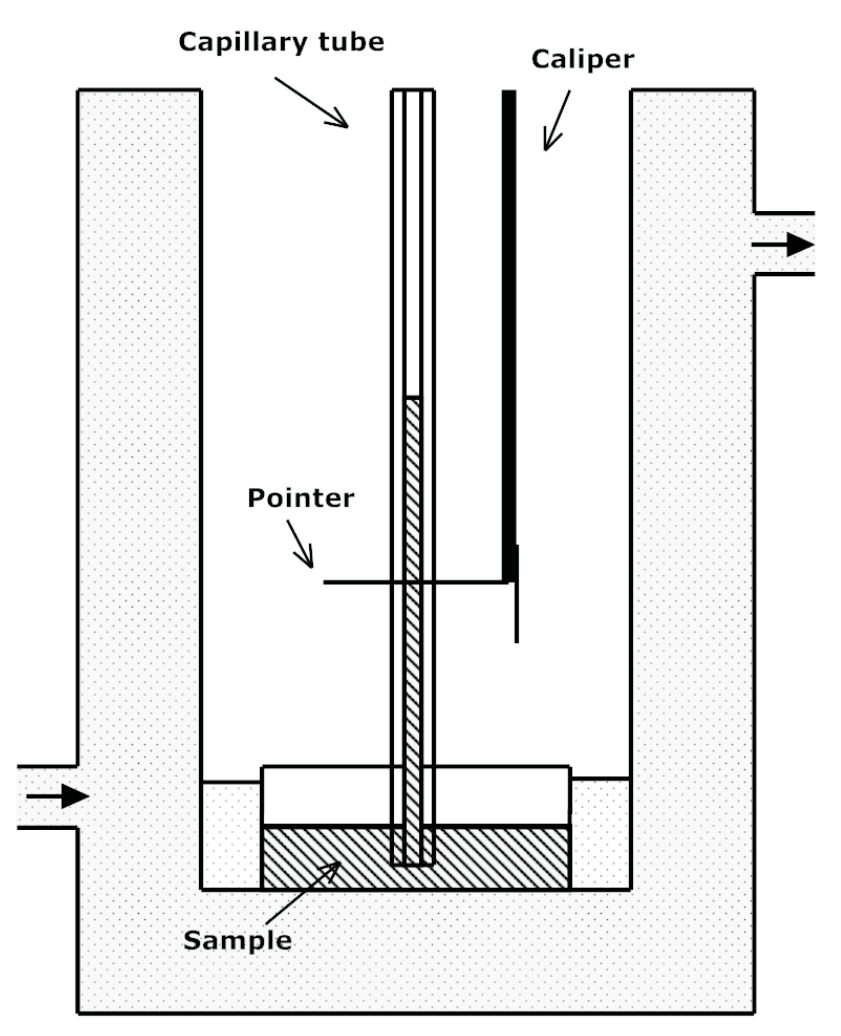

Fig. 1. Experimental setup.

can enhance the cloud droplet activation of mixed particles by decreasing the surface tension of the droplet (Cruz and Pandis, 1997, 1998; Li et al., 1998). The effect of various organic acids on the surface tension of water has been studied earlier (Shulman et al., 1996; Tuckermann and Cammenga 2004; Hyvärinen et al., 2006). There are also few measurements on the surface tensions of solutions containing both inorganic salt and organic acid (Bilde et al., 2004; Topping et al., 2006; Tuckermann 2007), but the data is scarce and cover usually only limited temperature and/or concentration range. There are also some studies where surface tensions of multicomponent systems have been calculated by using entirely predictive models ( $\mathrm{Li}$ and $\mathrm{Lu} 2001$; Topping et al., 2007). These models however seem to predict surface tensions of multicomponent mixtures quite poorly (Topping et al., 2007), and thus measurement data is generally needed to provide accurate predictions. Previous surface tension measurements show that the presence of inorganic salts can in some cases even enhance the surface activity of organic acids (Tuckermann, 2007; Kiss et al., 2005). The CCN number concentration has also been found to be quite sensitive to the decrease of surface tension caused by the presence of organic acids (Chang et al., 2007; Roberts et al., 2002).

There are only a few extensive data sets on surface tensions of ternary mixtures of atmospheric relevance. To this end, we studied the surface tension of ternary solution of sodium chloride, succinic acid and water as a function of both concentration and temperature. Succinic acid is a typical dicarboxylic acid found in aerosol phase (Legrand et al., 2007), and sodium chloride is a hygroscopic compound found in sea salt aerosols (Heintzenberg et al., 2000). This ternary solution can be thus considered as an atmospherically relevant mixture. The measured surface tensions were used as an input to an adiabatic air parcel model (Anttila et al., 2002) to study the effect of the surface tension on cloud droplet activation.

\section{Materials and methods}

\subsection{Experimental setup}

The surface tension was measured using a capillary rise technique (Fig. 1). The sample was placed in a small glass (about $20 \mathrm{ml}$ ) in the bottom of a double-walled glass. The temperature of the glass was controlled by circulating thermostatically controlled liquid between the walls (Lauda RC6 CS). To ensure effective heat transfer, the sample vessel was surrounded with water.

The samples were made of pure substances with purity of $99 \%$ or better (Table 1). The mixtures were made in a $50 \mathrm{ml}$ glass bottle and the weight of each compound was measured using a weighing balance Precisa junior $310 \mathrm{M}$ with uncertainty of about $0.1 \%$ (absolute accuracy $\pm 0.003 \mathrm{~g}$ ). This corresponds to an uncertainty of less than $0.5 \%$ in mole fraction. Both sodium chloride and succinic acid were dried before weighing in an oven at temperature of about $100^{\circ} \mathrm{C}$ to evaporate all the volatile impurities. Before every measurement the capillary tubes were cleaned using $96 \%$ sulfuric acid and purified water (Milli-Q).

The height of the liquid in the capillary tube was measured using a slide caliper modified to this purpose. Accuracy of the caliper is $\pm 0.02 \mathrm{~mm}$. A pointer made of thin plates of platinum and steel was mounted to the caliper to measure the distance from the surface of the bulk liquid to the bottom of the meniscus, normal to the capillary wall. Only the platinum plate was in contact with the sample. The measurements were performed in the temperature range of 283.15 to $303.15 \mathrm{~K}$. The meniscus was allowed to both rise and descent by altering the pressure in the tube. It was always checked if the meniscus stabilized in the same place when it was let to rise or descent. Uncertainty of the surface tension measurement was estimated to be less than $1 \%$.

\subsection{Calibration}

Two similar glass capillary tubes were used in the measurement. Both of them were calibrated using purified water (Milli-Q). The height of the water inside the tube was 
Table 1. Properties of the compounds used in this study.

\begin{tabular}{|c|c|c|c|c|c|c|c|}
\hline Compound & $\begin{array}{l}\text { Chemical } \\
\text { composition }\end{array}$ & $M[\mathrm{~g} / \mathrm{mol}]$ & $\begin{array}{l}\text { Solubility in } \\
\text { water at } 20^{\circ} \mathrm{C}[\mathrm{g} / \mathrm{l}]\end{array}$ & $\begin{array}{l}\text { Density of } \\
\text { aqueous solution } \\
{[\mathrm{mN} / \mathrm{m}]}\end{array}$ & $\begin{array}{l}\text { Surface tension } \\
\text { of pure compound } \\
{[\mathrm{mN} / \mathrm{m}]}\end{array}$ & Purity & Manufacturer \\
\hline Sodium Chloride & $\mathrm{NaCl}$ & 58.44 & $358.9^{\mathrm{d}}$ & $\begin{array}{l}\rho_{w}+44.85 c-0.096 c t+0.614 \\
\cdot 10-3 c t^{2}-2.712 c^{3 / 2}+0.01 c^{3 / 2} t^{\mathrm{e}}\end{array}$ & $191.16-71.88 e-3 T^{\mathrm{c}}$ & $99.5 \%$ & Carlo Erba Reagenti \\
\hline Succinic acid & $\mathrm{C}_{4} \mathrm{H}_{6} \mathrm{O}_{4}$ & 118.09 & $\sim 88^{\mathrm{a}}$ & see Eq. 2 & $83.45-0.12 T^{\mathrm{b}}$ & ACS quality & J. T. Baker \\
\hline Water & $\mathrm{H}_{2} \mathrm{O}$ & 18.015 & - & $999.65+0.204 t-6.174 \cdot 10^{-2} t^{3 / 2 e}$ & $\begin{array}{l}93.66+9.13 \cdot 10^{-3} T \\
-0.28 \cdot 10^{-3} T^{2}\end{array}$ & Milli-Q & Milli-Q \\
\hline
\end{tabular}

$[t]={ }^{\circ} \mathrm{C} ;[T]=\mathrm{K} ;[c]=\mathrm{mol} / \mathrm{l}$

a Saxena et al., 1996.

b Hyvärinen et al., 2006.

c Janz et al., 1980.

d CRC 1998.

e Novotny and Söhnel 1988.

measured as a function of temperature. The surface tension can be calculated using equation (Bikerman, 1947):

$\sigma=\frac{1}{2} \rho g r\left(h_{0}+\frac{r}{3}\right)$,

where $\sigma$ is surface tension, $\rho$ is density, $g$ is acceleration due to gravity, $h_{0}$ is the height of the water surface inside the capillary tube and $r$ is the radius of the tube. Because the surface tension and the density of pure water are well known (see Table 1), the radius of the tube can be calculated using Eq. 1 . Water was used for calibration, because all the measured solutions were aqueous having surface tensions relatively close to the surface tension of pure water, thus resulting in similar capillary rising heights.

Radii of the capillary tubes are $198.37 \mu \mathrm{m}$ and $179.62 \mu \mathrm{m}$, with standard deviations of 0.90 and 0.62 respectively. Standard deviations were used as errors of the capillary tubes radiuses when calculating the error of the measured surface tension.

\subsection{Density of the ternary solution}

When measuring surface tension using the capillary rise technique, the density of the solution has to be known. We were not able to find literature data on the densities of the investigated ternary mixture. Therefore the density had to be estimated using known binary solution densities. The density of aqueous sodium chloride $\left(\rho_{13}\right)$ as a function of concentration and temperature has been reported earlier by Novotny and Söhnel (1988) (International Critical Tables 1928, Table 1).

According to previous measurements on the density of aqueous succinic acid (Hyvärinen et al., 2006), the density can be estimated using the definition of the density of ideal solution (Prausnitz et al., 1986):

$$
\frac{1}{\rho_{12}}=\frac{M_{1} x_{1}}{\rho_{1}\left[M_{1} x_{1}+M_{2}\left(1-x_{1}\right)\right]}+\frac{M_{2}\left(1-x_{1}\right)}{\rho_{2}\left[M_{1} x_{1}+M_{2}\left(1-x_{1}\right)\right]},
$$

where $\rho$ is density, $M$ is the molar mass and $x$ is the mole fraction. Indices 1 and 2 stand for water and succinic acid respectively. The ideality assumption is reasonable because succinic acid is a weak acid and thus not readily dissociate, and because the succinic acid is expected to behave ideally due to the low concentrations characteristic to this study (Bilde and Svenningsson 2004; Varga et al., 2007). Density of pure succinic acid was estimated using the Yen-Woods method (Yen and Woods, 1966) by Hyvärinen et al. (2006) (Table 1).

The density of the ternary solution can be estimated by taking the mass weighted average of the binary densities:

$\rho_{123}=\frac{w_{2} \rho_{12}\left(x_{t}\right)+w_{3} \rho_{13}\left(x_{t}\right)}{w_{2}+w_{3}}$, where $\left(x_{t}=x_{2}+x_{3}\right)$

$w$ is mass fraction and indices 1,2 , and 3 stand for water, succinic acid and sodium chloride respectively. In order to validate the use of equation 3 , four measurements of the density of the solution were made by using a pyknometer, The mole fractions of succinic acid were varied from 0.0015 to 0.007 and the mole fractions of sodium chloride from 0.02 to 0.06 . The maximum deviation between estimation and measurements was $0.2 \%$. This indicates that the estimation is highly accurate within the solubility limits of the both solutes.

\subsection{Cloud model}

The cloud model used in this study is a box model that simulates interactions between an aerosol population and water vapour inside an adiabatically rising air parcel (Anttila et al., 2002). A sectional representation is used to model the aerosol and droplets, which are assumed to be internally mixed. A detailed description of the model can be found in Anttila et al., 2002. 


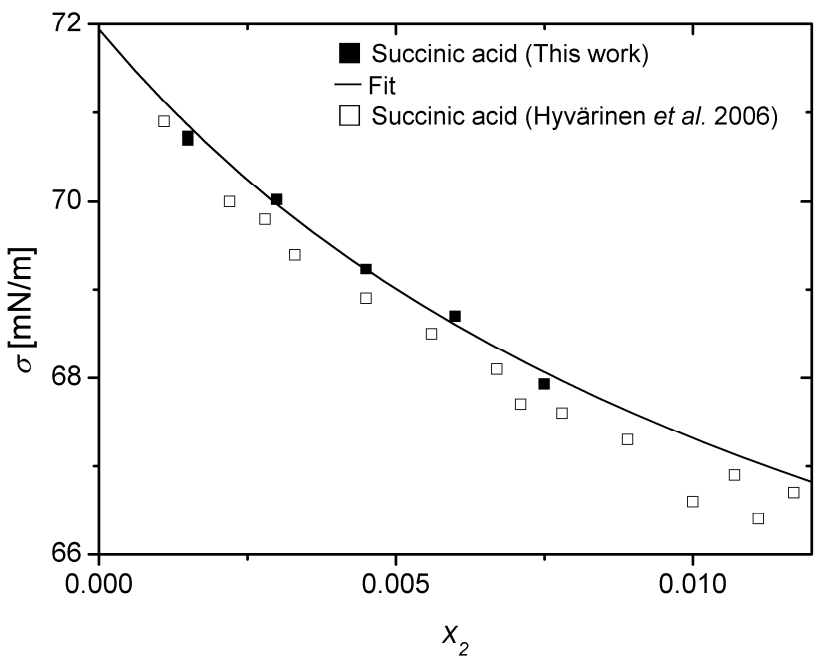

Fig. 2. Surface tensions of aqueous succinic acid as a function of the mole fraction of succinic acid $\left(x_{2}\right)$ at $25^{\circ} \mathrm{C}$.

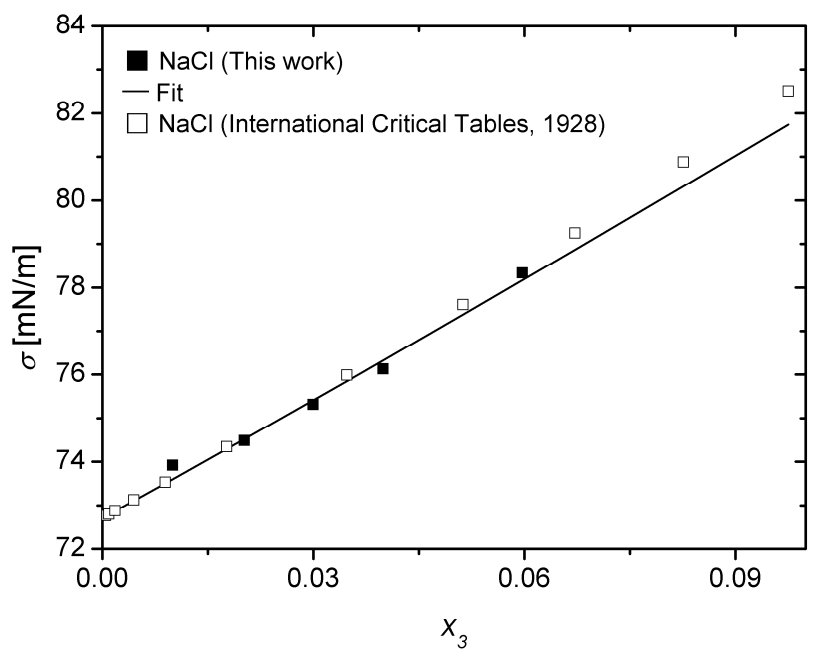

Fig. 3. Surface tension of aqueous sodium chloride as a function of the mole fraction of sodium chloride $\left(x_{3}\right)$.

\section{Results}

\subsection{Surface tension}

Surface tension of the ternary solution of sodium chloride, succinic acid and water was measured as a function of the mixture composition and temperature. The range of concentrations covered by measurements was limited by the solubilities of the investigated compounds. The maximum mole fractions used were 0.0075 and 0.06 for succinic acid and sodium chloride, respectively. The measured surface tensions are presented in Table 2.

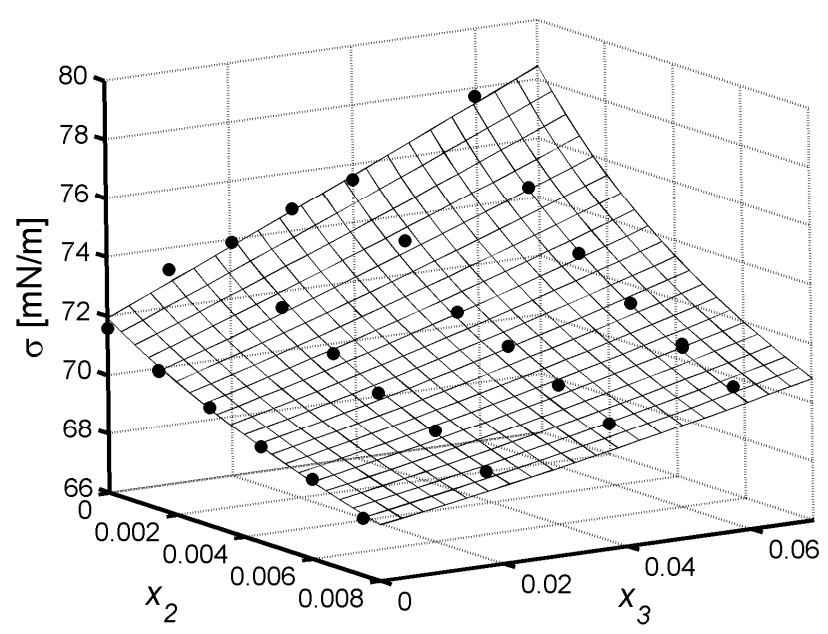

Fig. 4. Surface tension of the ternary solution of sodium chloride, succinic acid and water as a function of mole fractions of sodium chloride $\left(x_{3}\right)$ and succinic acid $\left(x_{2}\right)$ at $25^{\circ} \mathrm{C}$. Black dots are the measured surface tensions and grid is the fit to the data by Eq. 4 .

\subsubsection{Surface tensions of the binary solutions}

In Fig. 2 the surface tension measurements of aqueous succinic acid is presented and compared to the previous measurements made with the Wilhelmy-plate method by Hyvärinen et al., 2006. It can be seen that succinic acid decreases the surface tension of the solution already at quite small mole fractions. The surface tension is lowered by $3.0 \mathrm{mN} / \mathrm{m}$ at succinic acid mole fraction of 0.005 . Results agree well with the previous measurements done using a different method. Surface tensions measured with the capillary rise technique are systematically slightly higher, but the difference is not significant. Surface tension of aqueous sodium chloride is presented in Fig. 3. Sodium chloride increased surface tension linearly as a function of concentration. Results are compared to literature values (International critical tables, 1928), and a good agreement was found (maximum deviation of $0.6 \%$ ).

\subsubsection{Surface tension of the ternary solution}

In Fig. 4 the surface tension of the ternary solution is presented as a function of the mole fractions of succinic acid and sodium chloride at $25^{\circ} \mathrm{C}$. The decrease in the surface tension as a function of the succinic acid mole fraction becames steeper with increasing salt concentration. This indicates that succinic acid, as a surface active compound, tends to fill the surface of the solution. It has been found in previous studies that inorganic salts can even enhance the surface tension lowering tendency of organic acids, due to the fact that salt ions can drive organic acid molecules to the surface (Tuckermann, 2007; Kiss et al., 2005; Shulmann et al., 1996). This is the salting-out effect (Setschenow, 1889). Although this 
Table 2. Surface tensions $(\sigma)$ of ternary solution of sodium chloride, succinic acid and water. $T$ is temperature, $x$ is mole fraction and subscripts 2 and 3 represent succinic acid and sodium chloride respectively.

\begin{tabular}{|c|c|c|c|c|c|c|c|c|c|c|c|c|c|c|c|c|c|c|c|}
\hline$t\left[{ }^{\circ} \mathrm{C}\right]$ & $x_{3}$ & $x_{2}$ & $\sigma[\mathrm{mN} / \mathrm{m}]$ & $t\left[{ }^{\circ} \mathrm{C}\right]$ & $x_{3}$ & $x_{2}$ & $\sigma[\mathrm{mN} / \mathrm{m}]$ & $t\left[{ }^{\circ} \mathrm{C}\right]$ & $x_{3}$ & $x_{2}$ & $\sigma[\mathrm{mN} / \mathrm{m}]$ & $t\left[{ }^{\circ} \mathrm{C}\right]$ & $x_{3}$ & $x_{2}$ & $\sigma[\mathrm{mN} / \mathrm{m}]$ & $t\left[{ }^{\circ} \mathrm{C}\right]$ & $x_{3}$ & $x_{2}$ & $\sigma[\mathrm{mN} / \mathrm{m}]$ \\
\hline 10.2 & 0 & 0 & 73.5 & 15.2 & 0 & 0 & 73 & 20.2 & 0 & 0 & 72.3 & 25.1 & 0 & 0 & 71.6 & 30.1 & 0 & 0 & 71 \\
\hline 10.3 & 0 & 0.0015 & 72.7 & 15.3 & 0 & 0.0015 & 72.1 & 20.2 & 0 & 0.0015 & 71.5 & 25.2 & 0 & 0.0015 & 70.7 & 30.1 & 0 & 0.0015 & 70.1 \\
\hline 10.4 & 0 & 0.0015 & 72.4 & 15.3 & 0 & 0.0015 & 71.9 & 20.2 & 0 & 0.0015 & 71.3 & 25.2 & 0 & 0.0015 & 70.7 & 30.2 & 0 & 0.0015 & 70.1 \\
\hline 10.3 & 0 & 0.003 & 71.8 & 15.3 & 0 & 0.003 & 71.2 & 20.2 & 0 & 0.003 & 70.7 & 25.2 & 0 & 0.003 & 70 & 30.2 & 0 & 0.003 & 69.4 \\
\hline 10.3 & 0 & 0.0045 & 70.8 & 15.2 & 0 & 0.0045 & 70.4 & 20.2 & 0 & 0.0045 & 69.8 & 25.2 & 0 & 0.0045 & 69.2 & 30.2 & 0 & 0.0045 & 68.7 \\
\hline 10.4 & 0 & 0.006 & 70.1 & 15.2 & 0 & 0.006 & 69.6 & 20.2 & 0 & 0.006 & 69.2 & 25.2 & 0 & 0.006 & 68.7 & 30.1 & 0 & 0.006 & 68.1 \\
\hline 10.3 & 0 & 0.0075 & 69.3 & 15.3 & 0 & 0.0075 & 68.9 & 20.2 & 0 & 0.0075 & 68.4 & 25.1 & 0 & 0.0075 & 67.9 & 30.2 & 0 & 0.0075 & 67.5 \\
\hline 10.2 & 0.01 & 0 & 75.4 & 15.3 & 0.01 & 0 & 74.5 & 20.2 & 0.01 & 0 & 73.9 & 25.1 & 0.01 & 0 & 73.3 & 30.1 & 0.01 & 0 & 72.7 \\
\hline 10.2 & 0.02 & 0 & 75.7 & 15.2 & 0.02 & 0 & 75.2 & 20.2 & 0.02 & 0 & 74.5 & 25.1 & 0.02 & 0 & 73.9 & 30.1 & 0.02 & 0 & 73.3 \\
\hline 10.2 & 0.02 & 0.0015 & 73.9 & 15.3 & 0.02 & 0.0015 & 73.3 & 20.3 & 0.02 & 0.0015 & 72.8 & 25.1 & 0.02 & 0.0015 & 72.3 & 30.1 & 0.02 & 0.0015 & 71.7 \\
\hline 10.3 & 0.02 & 0.003 & 72.6 & 15.2 & 0.02 & 0.003 & 72.2 & 20.2 & 0.02 & 0.003 & 71.8 & 25.1 & 0.02 & 0.003 & 71.3 & 30.2 & 0.02 & 0.003 & 70.8 \\
\hline 10.4 & 0.02 & 0.0043 & 71.7 & 15.3 & 0.02 & 0.0043 & 71.3 & 20.2 & 0.02 & 0.0043 & 70.9 & 25.1 & 0.02 & 0.0043 & 70.4 & 30.1 & 0.02 & 0.0043 & 69.9 \\
\hline 10.3 & 0.02 & 0.006 & 70.9 & 15.2 & 0.02 & 0.006 & 70.5 & 20.2 & 0.02 & 0.006 & 70.2 & 25.1 & 0.02 & 0.006 & 69.8 & 30.2 & 0.02 & 0.006 & 69.2 \\
\hline 10.3 & 0.03 & 0 & 76.5 & 15.3 & 0.02 & 0.0075 & 69.9 & 20.2 & 0.02 & 0.0075 & 69.5 & 25.1 & 0.02 & 0.0075 & 68.9 & 30.1 & 0.02 & 0.0075 & 68.6 \\
\hline 10.3 & 0.04 & 0 & 77.2 & 15.2 & 0.03 & 0 & 75.9 & 20.2 & 0.03 & 0 & 75.3 & 25.2 & 0.03 & 0 & 74.8 & 30.1 & 0.03 & 0 & 74.1 \\
\hline 10.2 & 0.04 & 0.0015 & 75.3 & 15.3 & 0.04 & 0 & 76.7 & 20.2 & 0.04 & 0 & 76.1 & 25.2 & 0.04 & 0 & 75.5 & 30.2 & 0.04 & 0 & 75 \\
\hline 10.3 & 0.04 & 0.003 & 73.5 & 15.2 & 0.04 & 0.0015 & 74.9 & 20.2 & 0.04 & 0.0015 & 74.4 & 25.2 & 0.04 & 0.0015 & 73.9 & 30.1 & 0.04 & 0.0015 & 73.4 \\
\hline 10.3 & 0.04 & 0.0045 & 72.7 & 15.2 & 0.04 & 0.003 & 73 & 20.2 & 0.04 & 0.003 & 72.5 & 25.2 & 0.04 & 0.003 & 72.1 & 30.1 & 0.04 & 0.003 & 71.6 \\
\hline 10.3 & 0.06 & 0 & 79.3 & 15.2 & 0.04 & 0.0045 & 72.4 & 20.2 & 0.04 & 0.0045 & 71.9 & 25.1 & 0.04 & 0.0045 & 71.5 & 30.2 & 0.04 & 0.0045 & 71.1 \\
\hline 10.3 & 0.06 & 0.0015 & 76.6 & 15.2 & 0.06 & 0 & 78.8 & 20.2 & 0.04 & 0.006 & 71.2 & 25.2 & 0.04 & 0.006 & 70.7 & 30.2 & 0.04 & 0.006 & 70.3 \\
\hline 10.3 & 0.06 & 0.003 & 74.7 & 15.2 & 0.06 & 0.0015 & 76.2 & 20.2 & 0.06 & 0 & 78.3 & 25.2 & 0.04 & 0.0075 & 70 & 30.2 & 0.04 & 0.0075 & 69.6 \\
\hline \multirow[t]{7}{*}{10.2} & 0.06 & 0.0045 & 73.5 & 15.2 & 0.06 & 0.003 & 74.2 & 20.2 & 0.06 & 0.0015 & 75.7 & 25.2 & 0.06 & 0 & 77.7 & 30.1 & 0.06 & 0 & 77.2 \\
\hline & & & & 15.2 & 0.06 & 0.0045 & 73.1 & 20.2 & 0.06 & 0.003 & 73.8 & 25.2 & 0.06 & 0.0015 & 75.2 & 30.2 & 0.06 & 0.0015 & 74.8 \\
\hline & & & & & & & & 20.2 & 0.06 & 0.0045 & 72.7 & 25.1 & 0.06 & 0.003 & 73.5 & 30.1 & 0.06 & 0.003 & 73.1 \\
\hline & & & & & & & & 20.2 & 0.06 & 0.006 & 71.7 & 25.1 & 0.06 & 0.0045 & 72.4 & 30.1 & 0.06 & 0.0045 & 72 \\
\hline & & & & & & & & 20.2 & 0.06 & 0.006 & 71.7 & 25.2 & 0.06 & 0.006 & 71.5 & 30.2 & 0.06 & 0.006 & 71.1 \\
\hline & & & & & & & & & & & & 25.2 & 0.06 & 0.006 & 71.4 & 30.1 & 0.06 & 0.006 & 71.1 \\
\hline & & & & & & & & & & & & 25.2 & 0.06 & 0.0075 & 70.7 & 30.2 & 0.06 & 0.0075 & 70.2 \\
\hline
\end{tabular}

effect was not observed in our measurements, it can nevertheless take place in the considered system when the solution becomes supersaturated with respect to sodium chloride.

In Fig. 5 the surface tension of the ternary solution is presented as a function of temperature for four different mole fractions of succinic acid. The sodium chloride mole fraction is 0.02 . Surface tension of the solution decreased with increasing temperature as expected (Bikerman, 1970). The behaviour is similar also with other concentrations of sodium chloride. The gradient of surface tension with respect to the temperature gets lower with increasing concentrations of both solvents. This means that the temperature dependency of the surface tension is a function of the composition of the solution.

\subsubsection{Surface tension parameterization}

To make the measurement results useful for numerical models, they need to be extrapolated to a larger concentration and temperature range. To this end, a function by Chunxi et al. (2000) was fitted to the data. The equation is based on thermodynamical relations and can be written as (Chunxi et al., 2000):

$\sigma=\sum_{i} x_{i} \sigma_{i}-R T \sum_{i} \frac{x_{i}}{\sum_{j} x_{j} \Lambda_{i j}} \sum_{j} x_{j}\left(\frac{\partial \Lambda_{i j}}{\partial A}\right)_{T, P, x}$

where

$\Lambda_{i j}=\exp \left(-\frac{U_{i j}-U_{i i}}{R T}\right)$

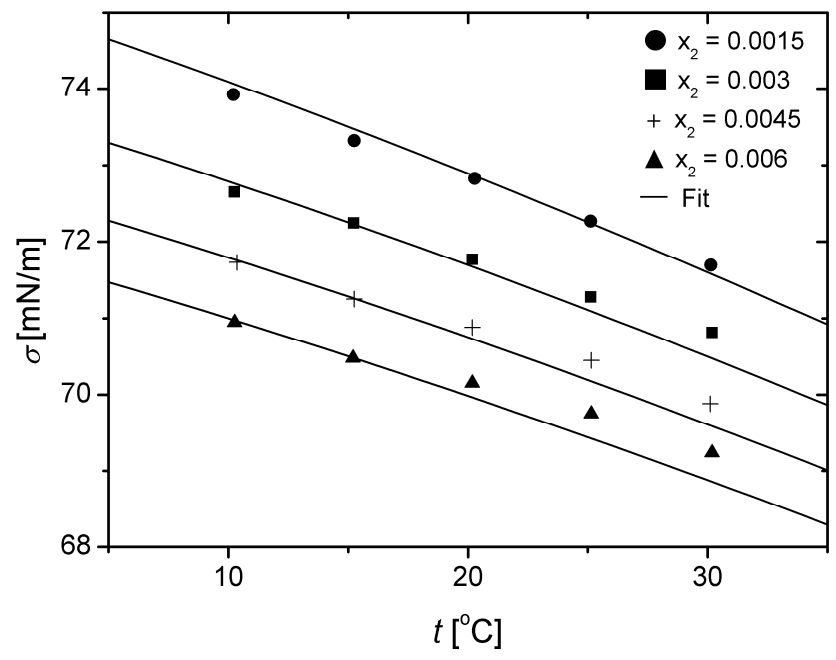

Fig. 5. Surface tension of ternary solution of sodium chloride, succinic acid and water as a function of temperature. Mole fraction of sodium chloride is kept constant $\left(x_{3}=0.02\right)$.

and

$\left(\frac{\partial \Lambda_{i j}}{\partial A}\right)_{T, P, x}=-\frac{\Lambda_{i j}}{R T}\left(\frac{\partial\left(U_{i j}-U_{i i}\right)}{\partial A}\right)_{T, P, x}$.

In Eq. 4 to $6, \sigma_{i}$ is the surface tension and $x_{i}$ is the mole fraction of compound $i, U_{i j}-U_{i i}$ is the difference in interaction energies of molecule pairs $i j$ and $i i, T$ is the temperature, $A$ 


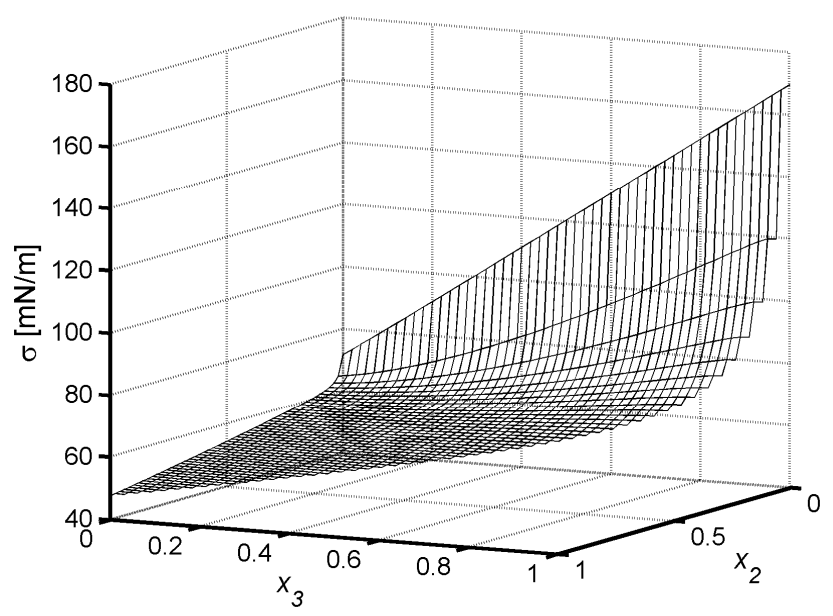

Fig. 6. The behaviour of the surface tension parameterization (Eq. 4) as a function of mole fractions $(x)$ of sodium chloride and succinic acid at $25^{\circ} \mathrm{C}$.

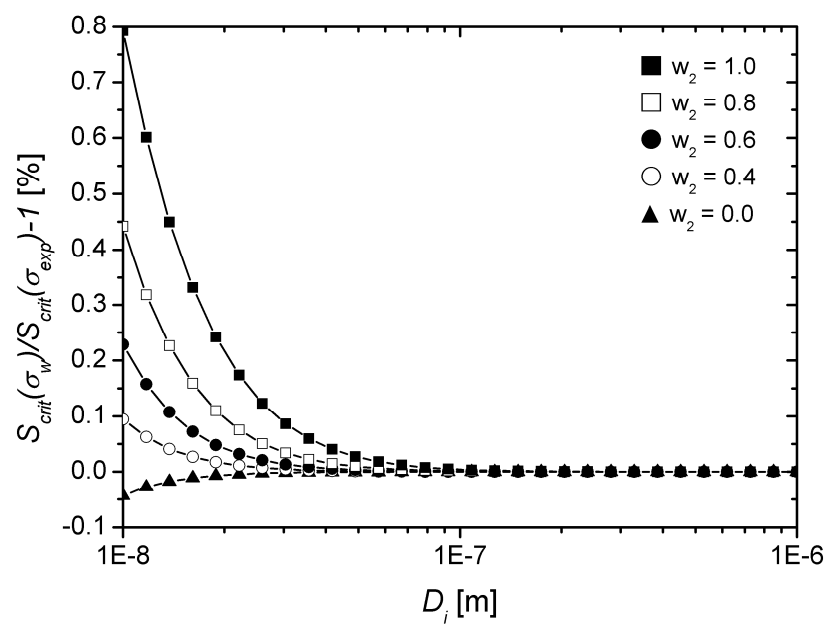

Fig. 7. Relative difference in critical supersaturations $\left(S_{\text {crit }}\right)$ obtained using different surface tensions. $w_{2}$ is the mass fraction of succinic acid, $\sigma_{w}$ is the surface tension of pure water and $\sigma_{\exp }$ is the surface tension parameterization.

is the surface area and $R$ is the universal gas constant. Parameters

$U_{i j}-U_{i i}$ and $\left(\frac{\partial\left(U_{i j}-U_{i i}\right)}{\partial A}\right)_{T, P, x}$

were used to fit the equation to the experimental data. Interaction energies can be calculated by using quantum chemistry, which makes the Eq. 4 also predictive.

A few assumptions had to be made in order to obtain a fit that represents the surface tension of the ternary solution beyond the solubility limits (Table 1). The surface tension of pure succinic acid was estimated using MagleodSugden method (e.g. Reid et al., 1987) as applied by Gaman
Table 3. Parameters for the Eq. 4.

\begin{tabular}{lcll}
\hline Parameter & \multicolumn{3}{l}{ Parameter } \\
\hline$U_{12}-U_{11}$ & -10803 & $\left(\frac{\partial\left(U_{12}-U_{11}\right)}{\partial A}\right)_{T, P, x}$ & -10.004 \\
$U_{13}-U_{11}$ & -4345.7 & $\left(\frac{\partial\left(U_{13}-U_{11}\right)}{\partial A}\right)_{T, P, x}$ & -8.7963 \\
$U_{21}-U_{22}$ & -467.93 & $\left(\frac{\partial\left(U_{21}-U_{22}\right)}{\partial A}\right)_{T, P, x}$ & -1.3523 \\
$U_{23}-U_{22}$ & 22980 & $\left(\frac{\partial\left(U_{23}-U_{22}\right)}{\partial A}\right)_{T, P, x}$ & -28093 \\
$U_{31}-U_{33}$ & 4175 & $\left(\frac{\partial\left(U_{31}-U_{33}\right)}{\partial A}\right)_{T, P, x}$ & 43.196 \\
$U_{32}-U_{33}$ & -8822.1 & $\left(\frac{\partial\left(U_{32}-U_{33}\right)}{\partial A}\right)_{T, P, x}$ & -108.89 \\
\hline
\end{tabular}

et al. (2004). This method estimates surface tensions of hydrogen bonded liquids with errors typically less than $10 \%$. A linear equation was fitted to the temperature dependent data (Table 1). This surface tension can be interpreted as the surface tension of succinic acid as subcooled liquid. Sensitivity analysis by Gaman et al. (2004) shows that the accuracy of the method is reasonable for atmospheric nucleation calculations. In the absence of relevant data, the surface tension for pure sodium chloride was estimated from molten salt surface tensions (Janz et al., 1980), and the results were extrapolated to the temperature range considered in this study. In Fig. 6, the behaviour of the surface tension parameterization is presented for the whole concentration range at $25^{\circ} \mathrm{C}$. Parameters for the Eq. 4 are presented in Table 3.

The obtained fit is presented in Fig. 2 to 6 as a solid line. The mean deviation of the fit from the measured surface tensions is $0.2 \%$, The fit is based on measurements conducted at temperatures from 10 to $30^{\circ} \mathrm{C}$, but it can be extrapolated with caution to somewhat higher and lower temperatures. The fit presented here can also be used beyond solubility limits with few cautions. No macroscopic phenomena, such as critical micelle concentration, are taken into account. It has to be also noted that the surface tensions of pure compounds are estimates, and consequently error are prone to increase with the increasing concentration of a solvent. In addition, the possible salting-out effect can not be predicted by this parameterization. Despite these uncertainties, the extended parameterization is applicable in models simulating microscopic phenomena such as nucleation.

As a comparison, we made also calculations in order to predict the surface tension of the ternary solution by using the known binary surface tensions (Hyvärinen et al., 2006; International critical tables, 1928). The simplest approach is to add the contributions of both inorganic and organic compound to the surface tension of pure water (Topping et al., 2007): 
$\sigma_{\text {mix }}=\sigma_{w}+\Delta \sigma_{\text {org }}+\Delta \sigma_{\text {inorg }}$,

where $\Delta \sigma_{\text {org }}$ and $\Delta \sigma_{\text {inorg }}$ are the deviations from the surface tension of pure water $\sigma_{w}$ caused by the presence of succinic acid and sodium chloride, respectively. A mean deviation of $2.9 \%$ was found when the results were compared with the measured surface tensions. This indicates that this simple predictive model is not capable in predicting the surface tension of the investigated ternary mixture with high accuracy.

\subsection{Cloud droplet activation}

3.2.1 Critical supersaturation of sodium chloride/succinic acid particles

Saturation ratio of water vapour over solution droplet can be calculated using Köhler theory (Köhler, 1936):

$S=a_{w} \exp \left(\frac{2 \sigma M_{w}}{r \rho_{w} R T}\right)$,

where $a_{w}$ is the water activity, $\sigma$ is the surface tension of the solution, $M_{w}$ is the molecular mass of water, $r$ is the radius of the droplet, $\rho_{w}$ is the density of water, $R$ is the universal gas constant and $T$ is the temperature. In Eq. 5 the exponential term accounts for the curvature effect (Kelvin effect) and the activity for the solute effect (Raoult effect). Here we focus on the effect of surface tension and assume that activity $a_{w}$ equals to the mole fraction of water $x_{w}$.

The maximum value of $S$ is called the critical supersaturation $\left(S_{\text {crit }}\right)$. If the saturation ratio of the environment exceeds the critical value, the droplet can activate and grow to larger sizes. Because the Köhler theory accounts for the surface tension of the solution, the difference of the critical supersaturations due to the surface tension used in the equation was investigated. The relative difference of critical supersaturations $\left[S_{\text {crit }}\left(\sigma_{w}\right) / S_{\text {crit }}\left(\sigma_{\text {exp }}\right)-1\right]$ is presented in Fig. 7 as a function of the particle dry diameter. The critical supersaturation is higher if the surface tension of pure water $\left(\sigma_{w}\right)$ is used, for all droplets except those containing only sodium chloride. Because surface tension is by definition the energy needed to increase the surface area, the critical supersaturation decreases with decreasing surface tension. It can be seen that surface tension has an effect only when the initial particles are smaller than $100 \mathrm{~nm}$ in diameter. The difference increases with increasing mass fraction of succinic acid.

Because succinic acid is a surface active compound, also the partitioning of the acid between the bulk solution and the surface should be taken into account (Sorjamaa et al., 2004). We made calculations of critical supersaturations for $40 \mathrm{~nm}$ and $170 \mathrm{~nm}$ particles. Partitioning was calculated using the Gibbs adsorption equation (Sorjamaa et al., 2004). By including the partitioning in the calculations we obtained almost the same critical supersaturations as using the surface tension of water without the partitioning, with an absolute error of less than $0.05 \%$. Such behaviour has been predicted
Table 4. Modes of the particle size distribution used in the cloud model simulations.

\begin{tabular}{llll}
\hline Mode & $\begin{array}{l}\text { Geometric mean } \\
\text { diameter }[\mathrm{nm}]\end{array}$ & $\begin{array}{l}\text { Geometric } \\
\text { standard } \\
\text { deviation }\end{array}$ & $\begin{array}{l}\text { Number of } \\
\text { particles } \\
{\left[\mathrm{cm}^{-3}\right]}\end{array}$ \\
\hline Aitken & 45 & 1.5 & 300 \\
Accumulation & 170 & 1.5 & 200 \\
\hline
\end{tabular}

also for humic-like substances by Sorjamaa and Laaksonen 2006 and Kokkola et al., 2006, and for multicomponent surfactant mixtures by Topping et al., 2007. Because the cloud nucleating ability of particles is mostly controlled by the critical supersaturations, and because the partitioning effectively compensates the surface tension reduction, we focused only on the extreme cases related to the effect of the surface tension on the cloud droplet activation.

\subsection{Cloud model simulations}

In order to investigate if surface tension has an effect on cloud droplet activation, we compared results from cloud model simulations that used two different surface tensions in calculating $S$ : that of pure water and that predicted by the developed surface tension parameterization. The parameter values describing aerosol size distribution used in the simulations are shown in Table 4. The distribution represents an aerosol size distribution that is typical in marine environment (Heintzenberg et al., 2000). Succinic acid is treated as a completely soluble compound despite of its solubility limit ( $88 \mathrm{~g} / \mathrm{l}$; Saxena et al., 1996). Previous studies have shown that the solubility of a slightly soluble compound has an effect only when there is no or very little of sodium chloride in the particle (Bilde et al., 2004). Also, particles have usually undergone various humidity conditions in the atmosphere. This means that the solution can be supersaturated with respect to succinic acid, and the infinite solubility assumption is reasonable. As mentioned earlier, bulk to surface partitioning of the solutes was not included in the model.

Cloud model simulations were made using three different updraft velocities; $0.1,0.5$ and $1.0 \mathrm{~m} / \mathrm{s}$. In Fig. 8 the ratio of the number of cloud droplets to the total number of particles (activated fraction) is presented as a function of the initial mass fraction of succinic acid in the aerosols. The activated fraction decreases as the mass fraction of succinic acid increases. This is because succinic acid has higher molar volume than sodium chloride and because sodium chloride is able to dissociate in water.

In Fig. 8, it can be seen that there is a difference in the number of cloud droplets arising from the choice of the surface tension. The difference increases with increasing mass fraction of succinic acid and with increasing updraft velocity. 


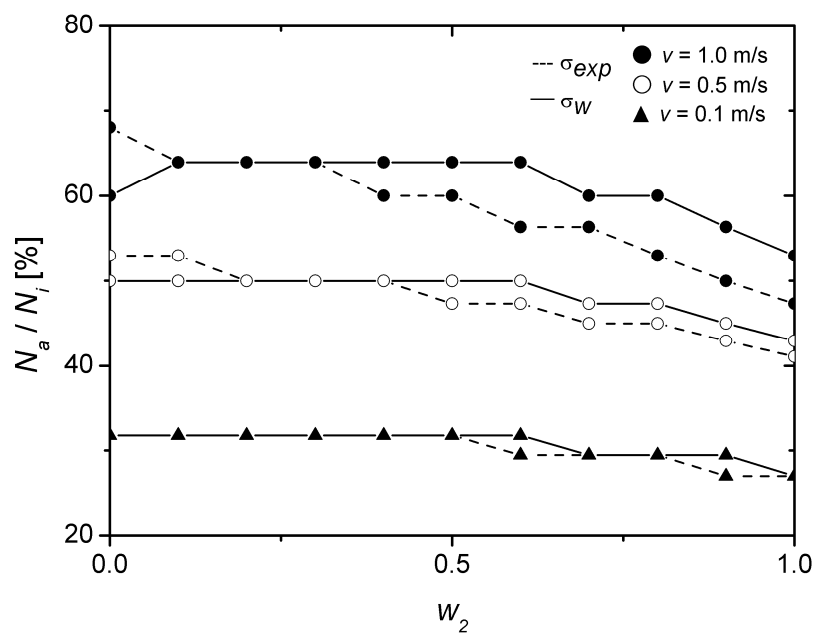

Fig. 8. Activated fraction as a function of mass fraction of succinic acid $\left(w_{2}\right) . v$ is the updraft velocity, $\sigma_{w}$ is the surface tension of pure water and $\sigma_{\exp }$ is the surface tension parameterization.

By using the surface tension of pure water in the cloud model the amount of activated particles is underestimated up to $8 \%$ when particles contained only succinic acid and overestimated up to $8 \%$ when particles contained only sodium chloride. This is because succinic acid decreases the surface tension while sodium chloride increases it. When the updraft velocity of the air parcel is $1.0 \mathrm{~m} / \mathrm{s}$, the effect of surface tension can be seen clearly with particles having a mass fraction of succinic acid over $40 \%$. The total mass fractions of organic compounds in atmospheric aerosol particles can easily exceed this value (Kanakidou et al., 2005). The decreasing importance of the surface tension with decreasing updraft velocity can be explained by larger dry diameters of activated particles, which is due to the lower updraft velocity, and thereby lower supersaturations reached in the air parcel. This decreases the magnitude of the Kelvin effect which depends on the surface tension of the solution. This has been also predicted to take place for marine aerosols by Nenes et al. (2002). Because the bulk to surface partitioning was excluded from these calculations (see Sect. 3.2.1), these results give the maximum effect of the surface tension on the cloud droplet activation.

\section{Conclusions}

In this study the surface tension of the ternary solution of sodium chloride, succinic acid and water was measured using the capillary rise technique. Both sodium chloride and succinic acid are found in atmospheric aerosols. Measured surface tensions of binary solutions agreed well with literature values, confirming that the method is applicable to these solutions. Measurements were performed within the concentration range defined by the solubility limits of the sol- vents. To estimate the surface tension beyond these limits, an equation developed by Chunxi et al. (2000) was fitted to the data. As a result a parameterization of surface tension of the ternary solution was obtained over the entire concentration range. The parameterization is based on the data for the temperature range of 10 to $30^{\circ} \mathrm{C}$, but the results can be extrapolated beyond these limits. There are many benefits with the developed kind of parameterization. First, it gives the surface tension of ternary system as a function of both the composition and temperature. Second, the parameterization is based on equations containing fit parameters which can be modelled. Because the parameterization can be used beyond solubility limits, it can be also applied, for example, in numerical calculations of nucleation or cloud droplet formation.

To estimate the atmospheric impact of the surface tension data, cloud droplet activation simulations were performed with particles of different composition. Three different updraft velocities $(0.1,0.5$ and $1.0 \mathrm{~m} / \mathrm{s})$ were used. It was found that while sodium chloride particles act as efficient cloud condensation nuclei, succinic acid can enhance the activation further by decreasing the surface tension of the aqueous solution. By using the surface tension of pure water in the cloud model the amount of activated particles was underestimated up to $8 \%$ if the initial particles contained succinic acid. For pure sodium chloride particles it was overestimated up to $8 \%$. Because the bulk to surface partitioning of the acid was not taken into account, these results describe only the effect of surface tension on the cloud droplet activation. Although the changes are small percent-wise, they still may have significance to the cloud radiative properties, in particular over the oceans. The marine clouds are usually clean clouds having lower number concentration of cloud droplets, which makes them especially sensitive to changes in the cloud droplet concentration (Platnic and Twomey, 1994). By including the bulk to surface partitioning, the effect of surface tension is effectively compensated. Becase of this, the results give the upper limit for the influence of surface tension to the cloud droplet activation.

Edited by: V. F. McNeill

\section{References}

Anttila, T. and Kerminen, V.-M.: Influence of organic compounds on the cloud droplet activation, J. Geophys. Res., 107(D22), 4662, 2002.

Bikerman, J. J.: Surface Chemistry; for Industrial Research, Academic Press Inc., Publishers, New York, 1947.

Bilde M. and Svenningsson, B.: CCN activation of slightly soluble organics: the importance of small amount of inorganic salt and particle phase, Tellus B, 56(2), 128-134, 2004.

Chang, R. Y.-W., Liu, P. S. K., Leaitch, W. R., Abbatt, J. P. D.: Comparison between measured and predicted CCN concentrations at Egbert, Ontario: Focus on the organic aerosol fraction at a semi-rural site, Atmos. Environ., 41, 8172-8182, 2007. 
Chunxi, L., Wenchuan, W., and Zihao W.: A Surface Tension Model for Liquid Mixtures Based on the Wilson Equation, Fluid Phase Equilibr., 175, 185-196, 2000.

CRC Handbook of Chemistry and Physics, 79th ed., edited by: Lide, D. R. and Frederikse, H. P. R., (CRC, Boca Raton, FL), 1998.

Cruz, C. N. and Pandis, S. N.: A study of the ability of pure secondary organic aerosol to act as cloud condensation nuclei, Atmos. Environ., 31(15), 2205-2214, 1997.

Cruz, C. N. and Pandis, S. N.: The effect of organic coating on the cloud condensation nuclei activation of inorganic atmospheric aerosols, J. Geophys. Res., 103, 13, 111-13,123, 1998.

Dusek U., Frank, G. P., Hildebrandt, L., Curtius, J., Scheider, J., Walter, S., Chand, D., Drewnick, F., Hings, S., Jung, D., Borrmann, S., and Andreae, M. O.: Size Matters More Than Chemostry for Cloud-Nucleating Ability of Aerosol Particles, Science, 312, 5778, 1375-1378, 2006.

Gaman, A. I., Kulmala, M., Vehkamäki, H., Napari, I., Mircea, M., Facchini, M. C., Laaksonen, A.: Binary homogeneous nucleation in water-succinic acid and water-glutaric acid systems, J. Chem. Phys., 120, 282-291, 2004.

Gershey, R. M.: Characterization of seawater organic matter carried by bubble-generated aerosols, Limnol. Oceanogr., 28, 309-319, 1983.

Heintzenberg, J., Covert, D. C., and van Dingenen R.: Size distribution and chemical composition of marine aerosols: A compilation and review, Tellus, 52B, 1104-1122, 2000.

Hyvärinen, A.-P., Lihavainen H., Gaman, A., Vairila, L., Ojala, H., Kulmala, M., and Viisanen, Y.: Surface Tensions and Densities of Oxalic, Malonic, Succinic, Maleic, and cis-Pinonic Acids. J. Chem. Eng. Data, 51, 255-260, 2006.

International Critical Tables; McGraw-Hill; New York, 1928; Vol. III.

IPCC (Intergovermental panel on climate change), Climate change 2007: The physical science basis, edited by: Solomon, S., Qin, D., Manning, M., Marquis, M., Averyt, K., Tignor, M. M. B., Miller, Jr., H. L. R., and Chen, Z., 2007.

Janz, G. J.: Molten Salts Data as Reference Standards for Density, Surface Tension, Viscosity, and Electrical Conductance: $\mathrm{KNO}_{3}$ and $\mathrm{NaCl}$, J. Phys. Chem. Ref. Data, 9, 791-830, 1980.

Kanakidou, M., Sinfeld, J. H., Pandis, S. N., Barnes, I., Dentener, F. J., Facchini, M. C., Van Dingenen, R., Ervens, B., Nenes, A., Nielsen, C. J., Swietlicki, E., Putaud, J. P., Balkanski, Y., Fuzzi, S., Horth, J., Moortgat, G. K., Winterhalter, R., Myhre, C. E. L., Tsigaridis, K., Vignati, E., Stephanou, E. G., and Wilson, J.: Organic aerosol and global climate modelling: a review, Atmos. Chem. Phys., 5, 1053-1123, 2005,

http://www.atmos-chem-phys.net/5/1053/2005/.

Kiss, G., Tombácz, E., and Hansson, H.-C.: Surface tension effects of humic-like substances in the aqueous extract of tropospheric fine aerosol. J. Atmos. Chem., 50, 279-294, 2005.

Kokkola, H., Sorjamaa, R., Peräniemi, A., Raatikainen, T., and Laaksonen, A.: Cloud formation of particles containing humic.like substances, Geophys. Res. Lett., 33, L10816, doi:10.1029/2006GL026107, 2006.

Kroll, J. H. and Seinfeld, J. H.: Chemistry of secondary organic aerosol: Formation and evolution of low-volatility organics in the atmosphere, Atmos. Env., 42, 3593-3624, 2008.

Köhler, H.: The nucleus in and the growth of hygroscopic droplets,
T. Faraday Soc., 32, 1152-1161, 1936.

Legrand, M., Preunkert, S., Oliveira, T., Pio, C. A., Hammer, S., Gelencsér, A., Kasper-Giebl, A., and Laj, P.: Origin of C2-C5 dicarboxylic acids in the European atmosphere inferred from yearround aerosol study conducted at a west-east transect, J. Geophys. Res., 112, D23S07, doi:10.1029/2006JD008019, 2007.

Li, Z., Williams, A. L., and Rood, M. J.: Influence of Soluble Surfactant Properties on the Activation of Aerosol Particles Containing Inorganic Solute. J. Atmos. Sci., 55, 1859-1866, 1998.

Li, Z. and Lu, B. C.Y.: Surface tension of aqueous electrolyte solutions at high concentrations - representation and prediction, Chem. Eng. Sci., 56, 2879-2888,2001.

McFiggans, G., Artaxo, P., Baltensperger, U., Coe, H., Facchini, M. C., Feingold, G., Fuzzi, S., Gysel, M., Laaksonen, A., Lohmann, U., Mentel, D. M., O`Dowd, C. D., Snider, J. R., and Weingartner, E.: The effect of physical and chemical aerosol properties on warm cloud droplet activation, Atmos. Chem. Phys., 6, 25932649, 2006, http://www.atmos-chem-phys.net/6/2593/2006/.

Nenes, A., Charlson, R. J., Facchini, M. C., Kulmala, M., Laaksonen, A., Seinfeld, J. H.: Can chemical effects on cloud droplet number rival the first indirect effect, Geophys. Res. Lett., 29(17), 1848, doi:10.1029/2002GL015295, 2002.

Novotný, P. and Söhnel, O.: Densities of Binary Aqueous Solutions of 306 Inorganic Substances, J. Chem. Eng. Data, 33, 49-55, 1988.

O‘Dowd, C. D., Lowe, J. A., and Smith, M. H.: Coupling sea-salt and sulphate interactions and its impact on cloud droplet concentration prediction, Geophys. Res. Lett., 26, 1311-1314, 1999.

Platnic, S. and Twomey, S.: Determining the Susceptibility of Cloud Albedo to Changes in Droplet Concentration with the Advanced Very High Resolution Radiometer, J. Appl. Meteorol., 33, 334-347, 1994.

Prausnitz, J. M.,Lichtenthaler R. N., and de Azevedo E. N.: Molecular Thermodynamics of Fluid-Phase Equilibria, 2nd ed., Prentice-Hall, Englewood Cliffs, NJ, 1986.

Pruppacher, H. R. and Klett, J. D.: Microphysics of Clouds and Precipitation, Kluwer Academic Publishers, Dordrecht, 2000.

Reid, R. C., Prausnitz, J. M., and Poling, B. E.: The Properties of Gases and Liquids, 4th ed., McGraw-Hill, New York, 1987.

Roberts, G. C., Artaxo, P., Zhou, J., Swietlicki, E., and Andreae, M. O.: Sensitivity of CCN spectra on chemical and physical properties of aerosols: a case study from the Amazon Basin, J. Geophys. Res., 107(D20), 8070, doi:10.1029/2001JD000583, 2002.

Saxena, P. and Hildemann, L. M.: Water-soluble organics in atmospheric particles: A critical review of the literature and application of thermodynamics to identify candidate compounds, J. Atmos. Chem., 24, 1, 1996.

Setschenow, J. Z.: Uber Die Konstitution Der Salzosungenauf Grunf auf Ihres Verhaltens Zu Kohlensure, Z. Physik. Chem., 4, 117-125, 1889.

Sorjamaa, R., Svenningsson, B., Raatikainen, T., Henning, S., Bilde, M., and Laaksonen, A.: The role of surfactants in Köhler theory reconsidered, Atmos. Chem. Phys., 4, 2107-2117, 2004, http://www.atmos-chem-phys.net/4/2107/2004/.

Sorjamaa, R. and Laaksonen, A.: The influence of surfactant properties on critical supersaturations of cloud condensation nuclei, Aer. Sci., 37, 1730-1736, 2006.

Shulmann, M, L., Jacobson, M. C., Carlson, R. J., Synovec, R. E., 
and Young T. E.: Dissolution behavior and surface tension effects of organic compounds in nucleating cloud droplets, Geophys. Res. Lett., 23(3), 277-280, 1996.

Taylor, J. P. and McHaffe A.: Measurements of Cloud Susceptibility, J. Atmos. Sci, 51, 1298-1306, 1994.

Tervahattu, H., Hartonen, K., Kerminen, V.-M., Kupiainen, K., Aarnio, P., Koskentalo, T., Tuck, A. F., and Vaida, V.: New evidence of an organic layer on marine aerosols, J. Geophys. Res., 107(D7), 4053, doi:19.1029/2000JD000282, 2002a.

Tervahattu, H., Juhanoja, J., and Kupiainen, K.: Identification of an organic coating on marine aerosol particles by TOF-SIMS, J. Geophys. Res., 107(D16), 4319, doi:10.1029/2001J001403, 2002b.

Topping, D. O., McFiggans, G. B., Kiss, G., Varga, Z., Facchini, M. C., Decesari, S., and Mircea, M.: Surface tension of multicomponent mixed inorganic/organic aqueous systems of atmospheric significance: measurements, model predictions and importance for cloud activation predictions, Atmos. Chem. Phys., 7, 2371-2398, 2007,

http://www.atmos-chem-phys.net/7/2371/2007/.
Tuckermann, R. and Cammenge, H. K.: Surface tension of aqueous solution of some atmospheric water-soluble organic compounds. Atmos. Environ., 38, 6135-6138, 2004.

Tuckermann, R.: Surface tension of aqueous solutions of watersoluble organic and inorganic compounds, Atmos. Environ., 41, 6265-6275, 2007.

Twomey, S.: The Influence of Pollution on the Shortwave Albedo of Clouds, J. Atmos. Sci., 34, 7, 1149-1152, 1977.

Varga, Z., Kiss, G., and Hansson, H.-C.: Modelling the cloud condensation nucleus activity of organic acids on the basis of surface tension and osmolality measurements, Atmos. Chem. Phys., 7, 4601-4611, 2007, http://www.atmos-chem-phys.net/7/4601/2007/.

Warner, J.: The supersaturation in natural clouds. J. Rech. Atmos. 3, 233-237, 1968.

Yen, L. C. and Woods, S. S.: A generalized equation for computer calculation of liquid densities, AIChe Journal, 12, 95-99, 1966. 